\title{
Apresentação: leitura e experiência
}

\author{
Presentation: reading and experience
}

Presentación: lectura y experiencia

Ligia Gonçalves Diniz* Patrícia Trindade Nakagome ${ }^{* *}$

Em literatura, antes de toda produção crítica ou teórica, vem o momento da leitura e da escuta. Circunscrever essa experiência em teoria ou crítica requer um gesto que não é simples; qualquer que seja o viés proposto, é do apuro desse gesto que emerge uma crítica ou uma teoria fecunda e generosa, não propriamente com as obras de que se ocupam, mas com a literatura em si própria, em todas suas possibilidades.

Antes, porém, do gesto de transformar a experiência literária primeira em discurso, há um movimento, necessariamente feito, mesmo quando inconscientes os leitores disso. Trata-se do ato de conceber uma noção do que significa, afinal, interagir com um texto literário. E mesmo quem nunca tenha parado para pensar nisso tem em si um rascunho mental do conceito de leitura. Nas consciências de críticos e teóricos, nos melhores casos, há mais do que um mero esboço da resposta para a pergunta: o que é ler um romance, um conto, um poema?

São da essência da experiência viva da leitura, entremeados ao ato intelectual, certo abandono do indivíduo ao texto e uma ilogicidade inerente à dimensão afetiva desse processo. Com isso, é fundamental forjar uma concepção desse gesto que dê conta da conversão do que existe de alheio ao logos em um formato discursivo, passível de ser comunicado.

Experiência é uma palavra inquieta, e não a colocamos à toa no título desta seção temática. Na língua alemã, há, para o termo único em português, duas traduções possíveis, que evocamos aqui para expressar as camadas latentes à atividade da leitura. Observando os elementos que compõem os vocábulos, entendemos a diferença entre eles: na raiz de Erlebnis, encontramos Leben (vida); já em Enfahrung, temos Fahrt (trajeto).

Hans-Georg Gadamer (2004, p. 53) define o verbo referente ao primeiro termo, Erleben, como "estar vivo quando algo acontece", e destaca ao mesmo tempo o aspecto imediato da apreensão do real característico dessa fase da experiência e a intensidade inerente a ela. Subjetiva ao extremo, a Erlebnis, diz Gadamer, não pode ser entendida como a dimensão, per se, da experiência estética. Existe, indelével, uma "pretensão humana à continuidade e à unidade da compreensão de si", escreve ele, que requer a "qualidade integradora da Erfahrung" para que um objeto estético seja vivenciado de forma completa, já que "arte é conhecimento, e experienciar uma obra de arte significa compartilhar esse conhecimento" (Gadamer, 2004, p. 84).

Temos na passagem de Leben a Fahrt - do instante de vida ao trajeto (concluído) - uma espécie de alegoria lexical do que é a atividade acadêmica no âmbito dos estudos literários. Acordamos diariamente como indivíduos leitores, transmutamo-nos ao longo do dia em produtores e compartilhadores de sentido e conhecimento. Como se opera esse deslocamento? Em nota a um ensaio no qual lê, lado a lado, o grego arcaico Simônides de Ceos e o alemão Paul Celan, a poeta e classicista Anne Carson escreve que há muito dela mesma em sua escrita e recusa-se a tomar como exclusiva a prescrição de Lukács segundo a qual a estrutura estética justa é uma mônada sem janelas: "Sempre me esforcei para levar meu pensamento ao campo da ciência e dos fatos, onde outras pessoas debatem logicamente e trocam julgamentos - mas fico cega por lá". Escrever, ela continua, envolve deslocar-se constantemente entre essa paisagem

\footnotetext{
* Doutora em Teoria Literária e Literaturas e pós-doutoranda na Universidade Federal de Minas Gerais (UFMG), Belo Horizonte, MG, Brasil. (Dorcid.org/0000-0003-2382-6158. E-mail: ligiadiniz@ gmail.com

** Doutora em Letras e professora da Universidade de Brasília (UnB), Brasília, DF, Brasil. (Dorcid.org/0000-0002-2921-9087. Email: patricia.nakagome@gmail.com
} 
escura em que os fatos do mundo se espalham e "uma sala sem janelas depurada de tudo o que não conheço" (Carson, 1999, loc. 50-60).

Carson compreende a complexidade do movimento de fazer do que é individual algo compartilhável em escrita. "É a depuração que toma tempo. É a depuração que é um mistério", ela diz. "Uma vez depurada, a sala escreve a si mesma. Copio os nomes de tudo o que sobra nela e anoto a atividade deles". Ela também não sequestra o que há de criativo no trabalho crítico, ao reconhecer que (ainda nos termos de Lukács) a receita a ser perseguida na atividade estética é aquilo com que também nós esbarramos nos nossos "melhores momentos". A consciência produtiva é, de fato, um espaço sem janelas - o que não quer dizer não alimentado por todos os nossos encontros com o mundo -, "trancado em suas próprias pressões, pescando fatos da paisagem em notas ou na memória tão bem quanto pode - vibrando (como diria Mallarmé) com seu desaparecimento" (Carson, 1999, loc. 60).

Carson justapõe vibração e atenção: é nesse encontro que leitura se metamorfoseia em escrita. "Pessoas veem de diferentes modos como representar a vibração, [...] o importante é anotar qualquer vibração que você perceber enquanto sua atenção estiver firme" (Carson, 1999, loc. 60). Atenção, diz ela, é a tarefa que todos nós que escrevemos sobre literatura (mas não só) compartilhamos. Manter a atenção firme, aprendemos com a autora, significa evitar que ela se acomode. Carson, no livro em questão, realiza isso fazendo dois homens, separados por 25 séculos, falarem ao mesmo tempo.

Nos artigos que reunimos nesta seção temática, encontramos autores que se dedicaram, em diferentes perspectivas, a encarar formas de fazer vibrar a atenção da leitura e sua conversão em escrita. Esse movimento pode ser realizado de muitos modos: seja por meio do contato direto com o texto literário e do que emerge desse encontro; seja a partir do pensamento rigoroso, teórico, apenas indiretamente informado pela leitura de obras específicas, aparecendo aqui em uma expressão delas abstraída; seja, ainda, por uma observação de viés institucional, observando-se a leitura de literatura em contextos amplos, como a escola e o mercado editorial.

Abrimos a seção com o artigo "Writing, Experience, and Literary Experience in Montaigne's Essays and Sartre's Nausea", em que Chad Córdova explora o conceito de experiência - esse conceito que o autor descreve como "óbvio, palpável e ainda assim misterioso". Observando a noção sobretudo pelo seu aspecto já circunscrito em significação, ainda que não em viés teleológico, Córdova reflete sobre uma relação entre literatura e experiência que se estabelece sobretudo por exclusão: o mundo dos livros seria aquele ao qual a experiência é um animal hostil, mas ainda assim do qual depende para se afirmar como experiência. Os casos de Montaigne e Sartre mostram que a ambiguidade ainda é mais profunda e abrem espaço para um questionamento de viés historicista: do século 16 ao 20, teria o locus da experiência por excelência se transportado da "vida" rumo à arte?

Alexandre Nodari desloca a questão ao propor, em "Alterocupar-se: obliquação e transicionalidade na experiência literária", que a leitura pressupõe um movimento em que o sujeito mantém sua posição original assumindo, a um só tempo, também a função de objeto de si mesmo, em um jogo de desdobramentos que extrapola tanto a reflexividade quanto a vivência empática da alteridade. É Clarice Lispector quem sopra a ideia de obliquação, e vem, sobretudo, da leitura de Água viva a sugestão de que toda interlocução habita um "leve desencontro" que produz um "quase" entendimento. A experiência literária não mais se opõe à experiência da "vida", mas evidencia-a, inflamada, na medida em que as personagens literárias existem como "egos experimentais", não metafórica mas heterotopologicamente, tornando a leitura um gesto consequente.

Os efeitos que a experiência literária dispara sobre o sujeito são também o foco de Conceição Aparecida Bento, em "Novas e antigas luminosidades", que toma livremente as ideias de Lacan a respeito do olhar e sua concepção de "objeto a" para pensar a relação entre as novas tecnologias de leitura e o indivíduo leitor. A aproximação entre olho e tato são substituídas pelo brilho das telas e uma nova forma de espacialização dos textos literários, propõe a autora, que questiona se haverá como consequência a perda da força do olhar como ato que atrai e capta o mundo, ao mesmo tempo que lança o sujeito a ele. Trata-se de uma preocupação que se reforça quando a atenção se volta à formação de novos leitores. 
Esta é o eixo também da discussão proposta por Rita Jover-Faleiros em "O que se ensina quando se ensina literatura? Considerações sobre a constituição de um objeto". No artigo, a autora reflete sobre o embate entre os campos da didática e dos estudos literários no que tange à sala de aula. A pergunta do título não é retórica, mas um estímulo a que não tomemos como dadas as possibilidades da literatura enquanto objeto de ensino. Defendendo a prioridade da leitura, Faleiros destaca a importância de um modelo que a encare como experiência de compartilhamento. Em "Uma estranha na sala de aula: interculturalidade, letramento literário e ensino", Marcelo Medeiros da Silva acompanha essa perspectiva, ao oferecer uma proposta de ensino para a leitura de poesia - gênero tomado comumente como o mais difícil. O autor defende, ainda, a maior presença de textos estrangeiros em sala de aula.

$\mathrm{O}$ apelo à leitura de literatura em sala de aula como compartilhamento coletivo da experiência encontra um contraponto na realidade. É o que vemos em "Dentro da nuvem do texto: analisando dados sobre consumo e apropriação de literatura entre estudantes". No artigo, André Carlos Moraes e Ana Gruszynski relatam os resultados de uma pesquisa feita com 667 estudantes universitários da Universidade Federal do Rio Grande do Sul a respeito de como entraram em contrato com as leituras obrigatórias para o vestibular. O estudo mostra uma profunda fragmentação e pluralidade de experiências.

Em outra faceta da perspectiva institucional da leitura de literatura, o artigo "Quem lê livros espíritas?" traz uma dupla mirada sobre um gênero consolidado no Brasil, a partir de um texto que concatena um estudo de viés sociológico, quantitativo e qualitativo, e uma experiência de leitura das próprias autoras, Ana Claudia da Silva e Verônica Bemvenuto de Abreu e Silva.

A experiência de leitura propriamente dita é a protagonista dos artigos seguintes. Em "O grau zero da ficção: desemolduramento enunciativo em Delírio de Damasco", Clarissa Loyola Comin se propõe a pensar em como as fronteiras borradas entre ficção e realidade, bem como entre gêneros, perturbam a própria experiência literária e a noção de literário mesma. $O$ texto de Veronica Stigger escolhido para conduzir o debate coloca tais questões de modo radical, na medida em que joga com uma dimensão "perigosa" da literatura, ao pôr a nu o gesto literário, por meio de frases recolhidas em ambiente público e "desemolduradas" (ou reemolduradas?) pelo suporte que se reconhece como próprio à literatura.

É também o deslocamento do real - neste caso a experiência da perda de uma filha - para as páginas de um romance o ponto de partida de Ricardo Augusto de Lima, em "'É preciso cuidado para não se perder': autoficção e experiência em O pai da menina morta, de Tiago Ferro". Aqui, contudo, o que lemos é, não a reflexão sobre uma experiência de leitura, e o que dela se deriva, mas ela própria em movimento. Notas se juntam a entradas de diário e fragmentos de reflexão para dar o contorno que se constrói à vista dos nossos olhos.

Em "Por uma anatomia do gesto literário: design de si e exercício crítico em Laura Erber", Edma de Góis compartilha com os leitores de seu artigo a vertigem da sua própria experiência, a partir da concepção, em Erber, de um eu poético que se dissimula por vezes na hábil evocação de outros autores, e por outras, paradoxalmente, na excessiva exposição da própria narrativa (e mesmo do próprio corpo escrito). Deparamos, assim, no artigo, com uma experiência de leituras superpostas e mesmo de metacrítica, na medida em que a poeta forja, em $A$ retornada, tanto uma inscrição de leituras quanto um esboço crítico de referências literárias.

Uma experiência de sobreposições também é o que temos em "A tradução como particular experiência de leitura: Triz, de Pedro Süssekind". Nesse artigo, Maria Célia Martirani debruçase sobre o protagonista Murilo, um tradutor que faz convergir, sobre o fio dos jogos de azar, sua vida e a obra que tem diante de si como tarefa, um romance russo (fictício) intitulado A aposta. A tradução é entendida aqui como uma forma particular, talvez mesmo privilegiada por mais envolvida, de leitura, o que leva o artigo para uma interessante discussão metalinguística.

A tradução aparece ainda, incidentalmente, no artigo de Enivalda Nunes Freitas e Souza e Erick Gontijo Costa, intitulado "Os livros e a vida da poesia de Dora Ferreira de Souza". Aqui é a experiência da vida que interrompe a linguagem, para ser depois retomada pela própria linguagem em poesia. Responsável por versões em português de obras de Rilke, entre outros, 
Dora Ferreira de Souza tem seu caminho literário pensado no texto de Souza e Costa: da natureza à palavra, que teria na poeta a função de ressacralizar o mundo. Os autores apontam, porém, a falsidade do conflito entre literatura e vida por outro viés, iluminando a filiação da autora - Blake, Rimbaud, Hölderlin, Drummond - e apontando o imaginário como dimensão de comunhão.

Os encontros afetivo-intelectuais também são os pontos de apoio do percurso que Kelvin Falcão Klein segue nas "Cenas de leitura em Silviano Santiago", do jogo ficcional com Graciliano Ramos de Em liberdade à transfiguração em Machado, passando pela leitura que faz do romance de Cyro dos Anjos O amanuense Belmiro, em que é o personagem Silviano que estende suas marcas ao autor Silviano Santiago. O que Klein ressalta é a importância dos episódios de leitura como pontos da costura de um amplo gesto crítico sobre a experiência literária entendida largamente.

Chegando ao final da seção temática, temos dois textos que ensaiam passos mais arriscados. Lia Duarte Mota traz os sentidos físicos do leitor para a cena em “Um corpo de leitura", em que lê conosco o romance Como se estivéssemos em palimpsesto de putas, de Elvira Vigna. O que Mota propõe é que há uma demanda do próprio texto para uma participação somática do leitor, como um disparo de uma energia de reverberação.

Encerrando o trajeto, Ricardo Araújo Barberena oferece um ensaio-experimento que reverbera ele próprio e nos convida ao compartilhamento da experiência. Concebido como um relato confessional de encontros com o escritor, em uma série de conferências, "Experiências com as leituras de João Gilberto Noll" é um texto que se faz escutar, em sua voz destoante, que intervém na dicção que se tenta estabilizar sem sucesso. Expõe assim, por seus efeitos explosivos, a fragilidade do formato esterilizado do artigo acadêmico quando o assunto é a experiência literária. Aqui, escrita, leitura e experiência vibram.

\section{O movimento do indizível}

É lugar-comum dizer que as obras literárias dependem do público para que possam de fato existir, e não apenas acumular poeira nas estantes. Mesmo quando o enfoque é o alcance de um sentido no texto literário, entendido este como um discurso com o qual compartilhamos um mundo, já não nos parece convir defender uma fidelidade da obra à realidade ou a busca de uma intenção autoral. Ainda assim, o quanto o leitor é, de fato, parte ativa (e criativa) na experiência literária ainda é objeto de um debate que ganha desdobramentos até o limite da própria definição do que é literatura, ou de conceitos vulcânicos como representação e ficção.

Em embate contra uma tradição que dá primazia a certa ordem duplicadora do real - e replicadora de normas e valores - na apreensão da literatura, Luiz Costa Lima propõe que a própria mímesis aristotélica sempre teve muito mais a ver com os efeitos provocados pela representação da realidade sobre a audiência do que com a reprodução de uma cena prévia, observada no mundo exterior. O sentido, escreve o autor, configura-se sempre a partir do horizonte de expectativas daquele que experimenta o texto, e "se comprova pelo efeito que provoca" (Lima, 2014, p. 162-163). Com essa releitura da mímesis, Costa Lima (2014, p. 30) toma da antiguidade uma lição tão essencial à contemporaneidade: a de que "é preciso aprender a viver sobre dupla via e não sobre a via única da verdade alcançada pelo pensamento".

É ainda no movimento entre vida e logos que nosso gesto paira. Isso porque, como diz alhures ainda Costa Lima (2013, p. 298), toda experiência estética, incluindo a literária, "não se esgota na arte nem [...] permite a determinação direta do objeto de arte. Em lugar disso e daquilo, a experiência estética oferece outra visão de mundo: a de que, apesar das leis que atuam na natureza, é próprio do mundo não ser controlável".

Extrapolando um pouco o que sugere Costa Lima, é isto o que cada um de nós aprende ao dar voz à nossa porção leitor: há um primeiro momento em que somos amparados e desamparados pela palavra a um só tempo; amparados pela palavra como um estímulo que dispara essa experiência, e desamparados na insuficiência dela no que significa trazer essa experiência de volta ao mundo. E isso revela algo que vai além da relação que estabelecemos com a literatura. 
Dedicado a refletir sobre o duradouro apego dos humanos às histórias, Wolfgang Iser qualificou sua teoria da imaginação e do fictício como "antropológica" precisamente por entender que existe algo de essencial à natureza humana que faz que nos voltemos às narrativas ficcionais para nos encontramos com uma dimensão do nosso ser que nos está indisponível na vida cotidiana. Existimos, isso é certo, mas não sabemos o que é a existência: não podemos ter a percepção da nossa existência de fora - por isso, a criamos e experimentamos aquelas que outros criam 'para nós'.

Para Iser (1993, p. xi), a imaginação assegura à literatura um substrato de uma maleabilidade que se manifesta "na reconfiguração contínua das formas culturalmente condicionadas que os seres humanos assumem". O valor fundamental disso - que garante a sobrevivência da literatura em meio às outras artes e manifestações culturais - é, ainda segundo o autor, que a experiência literária permite experimentarmos uma variação ilimitada de modelos, sendo um "espelho da plasticidade humana" e, assim atendendo nosso desejo de "estarmos presentes diante de nós mesmos".

O fictício, em contato com o imaginário, nos diz Iser (1993, p. 83), proporciona uma espécie de síntese da totalidade da experiência - que compreende atualidades, mas também potencialidades -, uma vez que "oferece a oportunidade paradoxal (e, talvez por isso, desejável) aos seres humanos de existir em meio à vida e simultaneamente ultrapassá-la". Ao vivenciarmos um texto literário, existimos no limiar entre real e fictício, e nossa imaginação é, por definição, um espaço de deslocamento duplo e oscilante entre mundos, que nos possibilita, nas palavras de Iser (1993, p. 86), "nos presentificarmos a nós mesmos como o nosso diferente".

O princípio subjacente aqui é que as possibilidades humanas não são derivadas da realidade, e sim as precedem: o mundo de fato seria, assim, produzido desde essa profusão de mundos possíveis e, como corolário, cada um de nós é não apenas o que somos de fato, mas, a cada momento, a profusão de nossas possibilidades, dentre as quais vamos desdobrando opções específicas. Esse número ilimitado de possibilidades "jamais pode estar presente para eles porque, como iniciadores de suas próprias possibilidades, sempre as precederiam" (Iser, 1993, p. 235-236). O autor continua, mais adiante:

Os seres humanos, entendidos como o desdobrar de si mesmos, nunca podem estar plenamente presentes diante de si, já que, a cada instante, só existem em uma única possibilidade realizada, e é isto o que eles não são: uma única possibilidade limitada de si. O desdobrar-se contínuo deve se manter por meio da encenação do plenum de possibilidades em uma constante alternância de processos de composição e decomposição de mundos fabricados (Iser, 1993, p. 236, grifos nossos).

Não se trata de retomar o velho clichê pré-moderno de que ler literatura nos ensina a ser melhores cidadãos, tampouco de recuperar o humanismo mais raso segundo o qual, ao nos colocarmos nos sapatos dos outros, nos tornamos automaticamente indivíduos mais empáticos. A questão aqui é menos social, e mais existencial: dependemos da interação en tre fictício e imaginário para sermos humanos, em todo o seu "tenebroso esplendor", para descarrilhar a expressão de Caetano Veloso. E essa interação, defende Iser e defendemos nós, encontra um lugar privilegiado na experiência literária, pelo tanto de investimento criativo e intelectual que ela demanda de nós na produção de significados e significações. Quando a imaginação é sequestrada por outras formas de ficção, que se impõem como reais, os riscos são enormes, como podemos ver em nosso contexto sociopolítico.

Também a experiência poética possibilita o que na vida cotidiana da linguagem, e em outras esferas do pensamento, não nos é cabível, ainda que fundamentalmente humano. Octavio Paz confere à noção de imagem, à qual praticamente faz corresponder a de poesia, precisamente este aspecto tão próprio a nós e tão negado: a coexistência de elementos mutuamente excludentes. "Épica, dramática ou lírica, condensada numa frase ou desenvolvida em mil páginas, toda imagem aproxima ou acopla realidades opostas, indiferentes ou afastadas entre si. Isto é, submete a unidade à pluralidade do real" (Paz, 2012, p. 104).

O mundo é contraditório - e nele os humanos - e a poesia nos exige que lidemos com isso, do mesmo modo que evidencia a não transparência das palavras. Ela, no entanto, 
também nos coloca em suspenso do ritmo do corriqueiro: abre parênteses para outro modo de estar atento, por meio da difícil tensão que constrói por meio da linguagem: "A experiência poética é irredutível à palavra e, não obstante, só a palavra a expressa. A imagem reconcilia os opostos, mas essa reconciliação não pode ser explicada com palavras exceto as da imagem, que já deixaram de sê-lo" (Paz, 2012, p. 117).

A imagem - feita de palavras que demonstram, por elas próprias, a simultânea insuficiência e potência das palavras - é, continua Paz, "um recurso desesperado contra o silêncio que nos invade toda vez que tentamos exprimir a experiência terrível daquilo que nos rodeia e de nós mesmos". Isso vale na produção e na leitura; não é pouco, e nos parece valer defender essa força tanto mais quanto com palavras se produz tanto o avesso disso hoje em nosso país: reiterações de expressões esvaziadas, reproduzidas roboticamente, de certezas calcadas em medos e ressentimento.

Mesmo sob a profusão de palavras que vivemos, as boas e más, importantes e nem tanto - ou justamente por essa abundância -, faz-se importante refletir sobre o indizível e seu papel na experiência literária, bem como na nossa tarefa de trazê-lo à tona em nossos trabalhos acadêmicos e em sala de aula. A filósofa portuguesa Maria Filomena Molder (2017, p. 77) sugere, acertadamente, que a linguagem só é vista como inimiga por aqueles que desejam vê-la como instrumento nu de acesso ao mundo, quando ela é, na realidade, tão simplesmente, "desejo de dizer". Decorre daí, diz a autora, que "mistério é que haja o que dizer, não o indizível":

O indizível aponta para uma tensão que o dizível transporta, não é um estranho à palavra, pelo contrário, a palavra concentra e guarda, às vezes petrifica de tão glorificado, um movimento, uma promessa, uma inquietação, inerentes a ela mesma e a que só ela pode acudir, que só ela pode engendrar. Indizível tem a ver com um desejo nunca satisfeito que nos faz correr (Molder, 2017, p. 77).

É assim que o discurso esvaziado nos imobiliza, nos distrai do que se mantém além dele inalcançável. Refletir sobre a leitura tendo a consciência de que há algo que nos escapa, escrever sobre essa experiência reconhecendo que uma porção dela se recusa à própria linguagem de que nos servimos para comunicá-la e dar sentido a ela: trata-se de um gesto de resistência do pensamento contra a imobilidade e o estado das coisas. "Manter o nosso dizer num querer dizer inextinguível previne contra o horror do desejo que se fez realidade", escreve Molder (2017, p. 79). Que os artigos que seguem coloquem o desejo vivo em movimento.

\section{Referências}

CARSON, Anne (1999). Economy of the unlost: reading Simonides of Keos with Paul Celan. Ed. Kindle Princeton: Princeton University Press.

GADAMER, Hans-Georg (2004). Truth and method. Tradução de Joel Weinsheimer; Donald G Marshall. 2. ed. New York: Continuum.

ISER, Wolfgang (1993). The fictive and the imaginary: charting literary anthropology. Baltimore: The Johns Hopkins University Press.

LIMA, Luiz Costa (2013). Frestas: a teorização em um país periférico. Rio de Janeiro: Contraponto; Editora PUC-Rio.

LIMA, Luiz Costa (2014). Mímesis: desafio ao pensamento. 2. ed. Florianópolis: Editora da UFSC.

MOLDER, Maria Filomena (2017). O terceiro incluído. In: MOLDER, Maria Filomena. Dia alegre, dia pensante, dias fatais. Lisboa: Relógio D’Água.

PAZ, Octavio (2012). O arco e a lira. Tradução de Ari Roitman e Paulina Wacht. São Paulo: Cosac Naify. 